\title{
Effect of Temperature on the Galvanic Corrosion of Cu-Ni Alloy/High Strength Steel in Seawater
}

\author{
WANG Chun $\mathrm{Li}^{1, \mathrm{a},{ }^{,}, \text {WU Jiang Hua }}{ }^{2, \mathrm{~b}}$ and YUAN Man ${ }^{1, \mathrm{c}}$ \\ ${ }^{1}$ College of Aerospace and Civil Engineering, Harbin Engineering University Harbin, China \\ ${ }^{2}$ state key laboratory for marine corrosion and protection, luoyang ship materials research institute \\ Xiameng, China

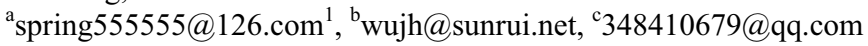

\begin{abstract}
The galvanic corrosion behavior of $\mathrm{Cu}-\mathrm{Ni}$ Alloy(B10)/high strength steel $(921 \mathrm{~A})$ has been studied using a zero-resistance ammeter (ZRA) in seawater at different temperatures. As well as it was systemically investigated by weight loss measurements, electrochemical methods and scanning electron microscope.Results showed $921 \mathrm{~A}$ acts as the anode and $\mathrm{B} 10$ act as the cathodes. The effect of temperature on the galvanic corrosion is important, the corrosion rate became higher with the temperature increased.
\end{abstract}

\section{Introduction}

Along with the development of ocean engineering technology, Marine engineering facilities are composed by many kinds of metal alloy materials[1,2]. Traditional materials supporting system are also constantly updated, so inevitably two or more metal occur electrical connection easy to form galvanic corrosion, that engineering design personnel adopted protective measures, such as coating, cathodic protection and insulation resistance and so on according to the existing research achievement $[3,4]$. But materials damage caused by galvanic corrosion still frequently happen in ocean engineering, After analyzing the causes, in addition to protective measures still needing to improve, corrosion behaviors rule and corrosion mechanism, influence factors all aspects should further study in the galvanic corrosion system[5-7].

As galvanic corrosion is great dangerous to safety of marine structures, the galvanic corrosion research on metal materials adopted by marine structures can provide data base and technical foundation for the design of material selection and corrosion protection, that has important theoretical significance and economic value. The objective of this work was to study the effect of temperature on the galvanic corrosion between $\mathrm{Cu}-\mathrm{Ni}$ Alloy(B10) and high strength steel(921A) in seawater by using the corrosion weight-loss method, electrochemical method and surface analysis techniques .

\footnotetext{
* Corresponding author:spring555555@126.com
} 


\section{Experimental Details}

The materials tested were $\mathrm{Cu}-\mathrm{Ni}$ Alloy(B10(10.13Ni, 0.0059C, $0.834 \mathrm{Mn}, 1.71 \mathrm{Fe}$, $0.026 \mathrm{Zn}, 0.01 \mathrm{~Pb}, 0.005 \mathrm{~S}$, Bal. $\mathrm{Cu})$ and the high strength steel $921 \mathrm{~A}(0.12 \% \mathrm{C}, 0.33 \% \mathrm{Si}$, $0.37 \% \mathrm{Mn}, 0.08 \% \mathrm{~Pb}, 0.04 \% \mathrm{~S}, 2.27 \% \mathrm{Ni}, 1.05 \% \mathrm{Cr}, 0.24 \% \mathrm{Mo}, 0.08 \% \mathrm{~V}$, Bal. Fe). The test samples with a size of $60 \mathrm{~mm} \times 20 \mathrm{~mm} \times 3 \mathrm{~mm}$ were made from the coupled materials whose surfaces were wet abraded from $100 \mathrm{SiC}$ (silicon carbide) grit to $600 \mathrm{SiC}$ grit then degreased with acetone and rinsed with absolute alcohol. And then measuring the sizes of specimen covered partially by use of Model AB glue in order to determine the working areas of materials of galvanic couples to $10 \mathrm{~cm}^{2}$. The specimens were stored in desiccators before use. Measurements were carried out in natural seawater collected from the North Yellow Sea and off the Qingdao Coast.

To carry out the galvanic corrosion test, the dissimilar metals were immersed face to face with distance of $8 \mathrm{~cm}$ in stagnant seawater then connected and their common potentials were followed with time until constancy. In test the galvanic corrosion currents were measured over a zero-resistance ammeter (ZRA). By inserting a ZRA in the electrical circuit that connects two members, it was possible to measure the galvanic current between members and simultaneously, the galvanic potential was registered against a saturated calomel electrode (SCE) as a reference electrode. The galvanic current and potential was measured at sampling rate of 1 point $\mathrm{h}^{-1}$. The ZRA was programmed to record 240 points potential and current plots for each hour of total $240 \mathrm{~h}$ measurement duration. Corrosion tests were carried out at $0,5,15,25,35,45$ and $65^{\circ} \mathrm{C}$. After $240 \mathrm{~h}$, the corrosion samples removed from the chamber and rinsed with deionized water. The surface morphologies of the samples were detected by SEM in order to estimate possible micro-structural variations. Energy dispersive $\mathrm{X}$-ray analysis (EDX) adopted to trace the galvanic corrosion production.

For the purpose of contrast, Weight loss measurements were carried out in seawater at different temperatures controlled by humidity chamber Model ESS-SDJ201. All the test solutions were open to air. The mass of cleaned and dried samples before and after corrosion in the test were determined by an analytical balance. After weighted, those samples were immersed in seawater for different temperature defined as immersion time. Then the immersed samples were rinsed thoroughly, the corrosion samples were dried and re-weighed accurately. Experiments were performed in each case and the mean value of the weight loss was calculated and used for the following analysis. The corrosion rate (Vt) was obtained according to Eq.1:

$$
V_{t}=\frac{8.76 \times 10^{7} \times\left(M-M_{1}\right)}{S T D}
$$

Where $\mathrm{M}$ and $\mathrm{M}_{1}$ are the mass of the sample before and after corrosion, respectively. $\mathrm{S}$ is the total surface area of the sample, $\mathrm{T}$ is the immersion time and $\mathrm{D}$ is density.

\section{Results and Discussions}

The Self-Corrosion Behavior of the Alloys. Fig. 1 and Fig. 2 respectively shows the self-corrosion potential data plots of $\mathrm{B} 10$ and $921 \mathrm{~A}$ at $0,5,15,25,35,45$ and $65^{\circ} \mathrm{C}$. From Fig.1, the self-corrosion potential of B10 with the temperature rise, is first shifted quickly to negative, potential changes from +0.099 to $-0.071 \mathrm{~V}$ with the temperature from $0^{\circ} \mathrm{C}$ to $5^{\circ} \mathrm{C}$, then, self-corrosion potential is almost the same at temperature from 5 up to $35^{\circ} \mathrm{C}$. the self-corrosion potential shifted to negative from -0.083 to $-0.243 \mathrm{~V}$ with the temperature from 
$35^{\circ} \mathrm{C}$ to $65^{\circ} \mathrm{C}$. which was attributed to the formation and increase of the oxide film thickness, the breakdown of passivated film make the potential of $\mathrm{B} 10$ shifted to negative above $35^{\circ} \mathrm{C}$.

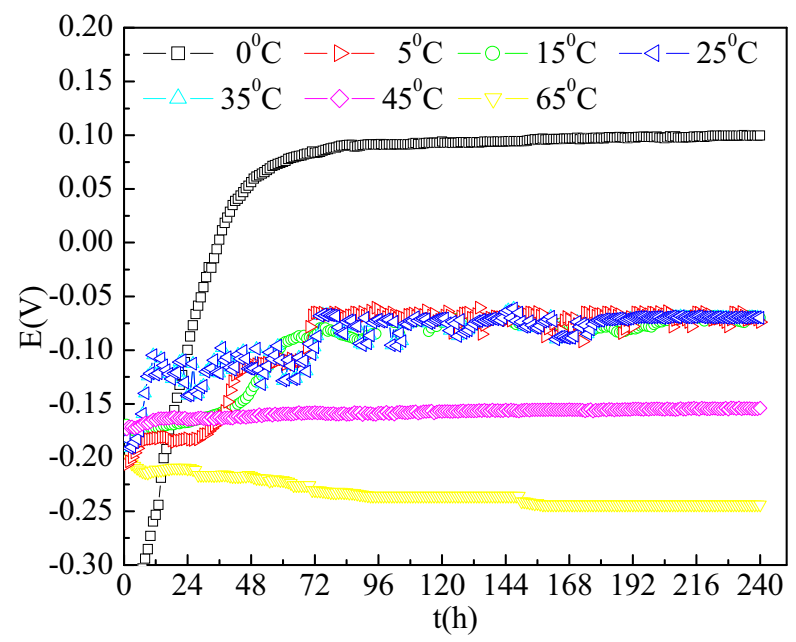

Figure1. Free corrosion potential of B10 in seawater with different temperature

As can be seen from Fig. 2 that the self-corrosion potential of 921A varies from $-0.702 \mathrm{~V}$ to $-0.798 \mathrm{~V}$, and it decreases about $0.1 \mathrm{~V}$ with the increase of temperature. The self-corrosion potential of $921 \mathrm{~A}$ move negatively by promoting anodic process as temperature increases. At the same time, the temperature rises leading to the decrease of dissolved oxygen concentration led also make the self-corrosion potential shifted toward negative.

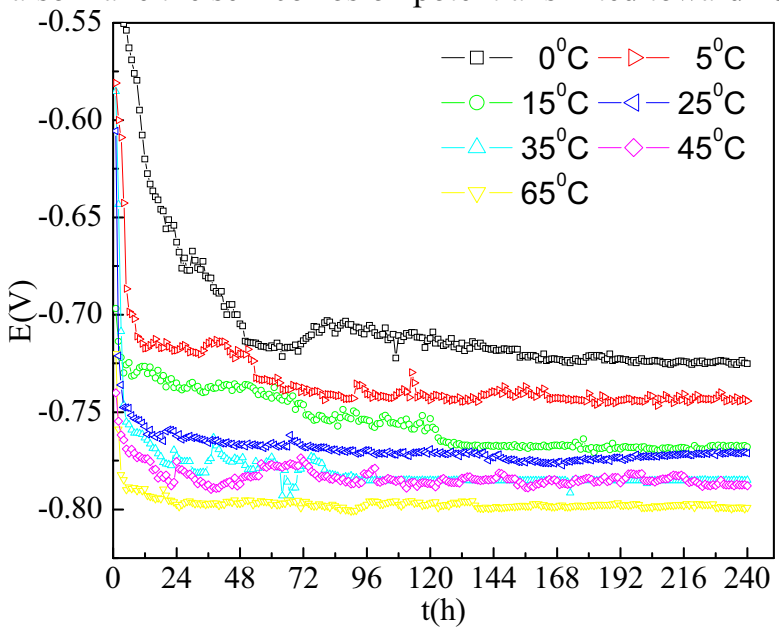

Figure2. Free corrosion potential of 921A in seawater with different temperature

A conclusion can be drawn from Fig. 3 that uncoupled single phases reveal that the electrochemical activity increases in the following order: $\mathrm{Cu}-\mathrm{Ni}$ Alloy $<$ high strength steel. For example, the self-corrosion potential of B10 was more than about $0.726 \mathrm{~V}$ to that of $921 \mathrm{~A}$ at $0^{\circ} \mathrm{C}$. In addition, status was almost similar at other temperature. Therefore, the galvanic interaction between these phases is clearly posed. That is to say, the high strength steel (921A) would act as the anode and $\mathrm{Cu}-\mathrm{Ni}$ Alloy(B10) act as the cathodes in the galvanic couple. 


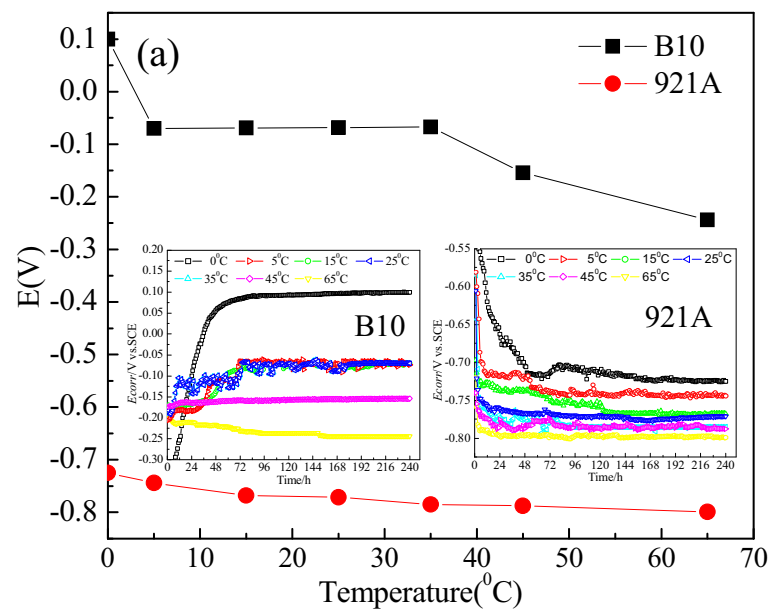

Figure3. Free corrosion potential plots of B10 and 921A in seawater with different temperature

Galvanic Current Density and Galvanic Potential. Fig. 4a shows the galvanic potential registered between $\mathrm{B} 10$ and $921 \mathrm{~A}$ in seawater at $0{ }^{\circ} \mathrm{C}$ to $65^{\circ} \mathrm{C}$. The galvanic potential shifted to more negative values during the two days and it tended to stabilise from the third day at any temperature. The increase of temperature caused the galvanic potential to shift to more negative values with acceleration of corrosion.

Results of the galvanic current density(Ig) shown in Fig. 4b demonstrate that $921 \mathrm{~A}$ acts as the anode and $\mathrm{B} 10$ act as the cathodes in galvanic coupling. Rising from $0{ }^{\circ} \mathrm{C}$ to $65{ }^{\circ} \mathrm{C}$, galvanic current density increased about 3 times, that had a greater influence on galvanic corrosion due to the change in temperature. Also it can be found that the galvanic potential value under different temperature conditions are close to $921 \mathrm{~A}$ of the self-corrosion potential. Potential of B10 has changed much in the action of smaller polarization current because of highly polarizable. Thus B10/921A galvanic potential value was close to the self-corrosion potential of $921 \mathrm{~A}$, and $921 \mathrm{~A}$ corrosion rate increases with temperature and potential negative shift. So the galvanic potential of B10/921A shifted accordingly in negative direction with temperature. 

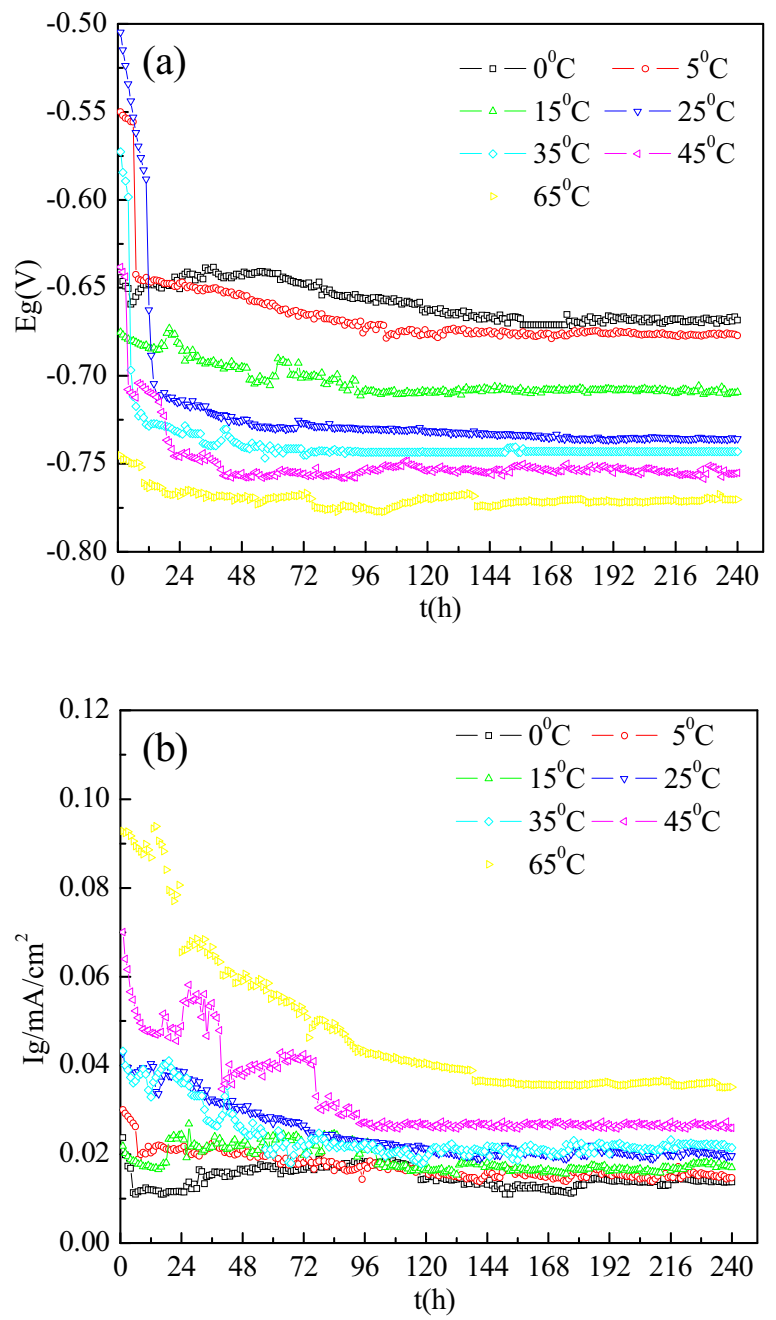

Figure4. Galvanic potential and galvanic current density of B10/921A coupling in natural seawater for 240h:

(a) galvanic potential; (b) galvanic current density

Fig. 5 illustrates the relationships between corrosion rate and temperature by weight loss measurements. Where $\mathrm{V}_{\mathrm{c}}$ and $\mathrm{V}_{\mathrm{g}}$ are the corrosion rate of the sample self and couple corrosion, respectively. Results showed that temperature is increased from $0{ }^{\circ} \mathrm{C}$ to $65^{\circ} \mathrm{C}$, corrosion rate of $921 \mathrm{~A}$ increased to $0.281 \mathrm{~mm} / \mathrm{a}$ from $0.116 \mathrm{~mm} / \mathrm{a}$. Corrosion rate of the 921A in coupling was about twice as much as that of self-corrosion. this means that the galvanic corrosion became more severe, the galvanic corrosion is highly affected by the temperature. 


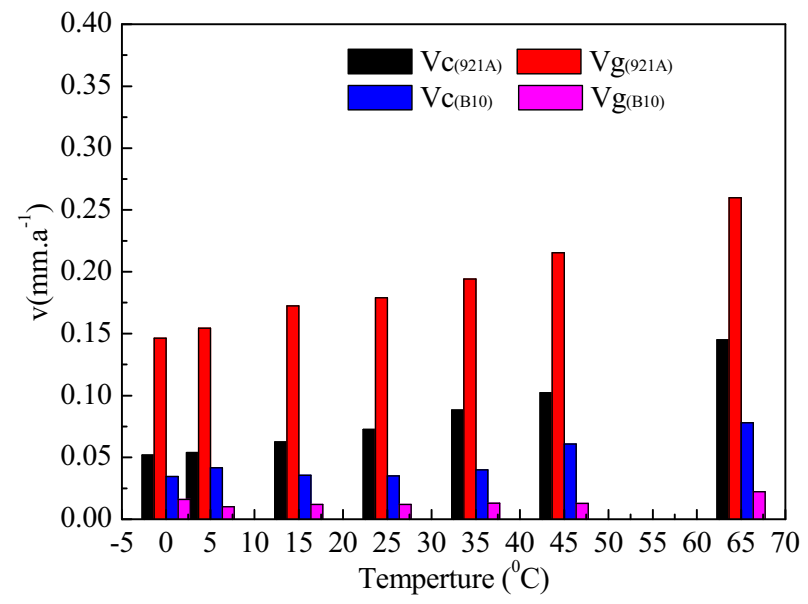

Figure5. Weight-loss method for B10 and 921A in seawater with different temperature

Micro-structural Examination. Fig. 6 and Fig. 7 present SEM micrographs of 921A and B10 surface obtained before and after cleaning electrically connected for $240 \mathrm{~h}$ immersed in natural seawater at $15^{\circ} \mathrm{C}$. It can be seen that $921 \mathrm{~A}$ as anode is suffered from galvanic corrosion(Fig.6a) greater than that of self-corrosion (Fig.6b), the B10 as cathodes is suffered from galvanic corrosion(Fig7a) lighter than that of self-corrosion (Fig7b).

By the EDX analysis, Yellow thick corrosion product of the 921A surface mainly for Fe and $\mathrm{O}$, The product was most likely $\mathrm{Fe}_{2} \mathrm{O}_{3}$ and $\mathrm{FeOOH}$. Above comprehensive analysis, anode reaction process of $\mathrm{B} 10 / 921 \mathrm{~A}$ under different temperature conditions would be iron dissolution reaction under the control of oxygen diffusion. Cathode B10 microscopic corrosion morphology shown in fig.7a that the surface corrosion products covered by the EDX analysis for the $\mathrm{Ca}(\mathrm{OH})_{2}$, it follows that the cathodic reaction was oxygen reduction reaction. After cleaning, the surface of B10 is smooth, even at high temperature, the corrosion degree is almost zero due to completely protected by galvanic effect.

\section{Summary}
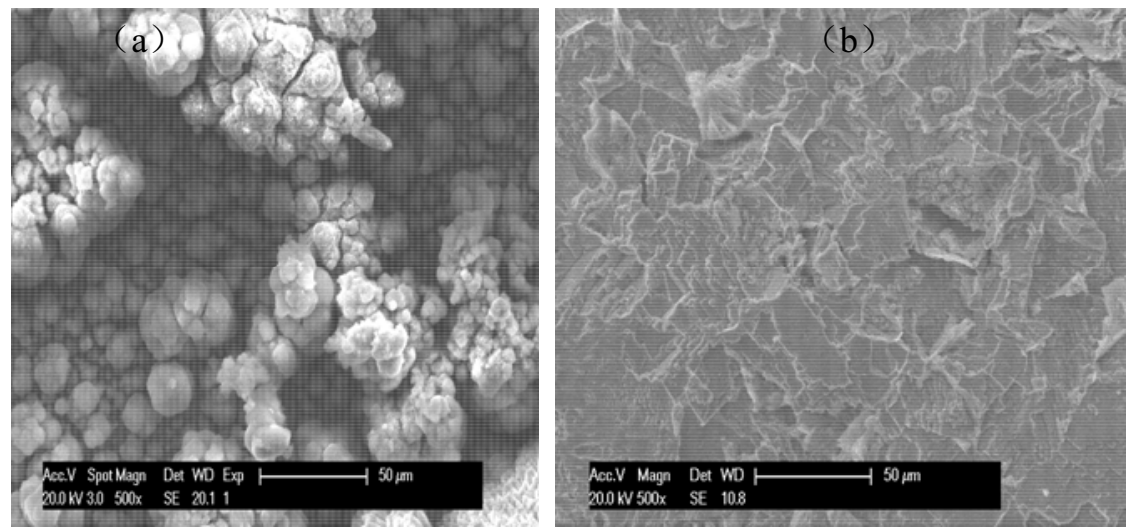

Figure6. SEM micrographs of $921 \mathrm{~A}$ in galvanic couple $\mathrm{B} 10 / 921 \mathrm{~A}$ in seawater at $15^{\circ} \mathrm{C}$ :

(a) SEM before cleaning, (b) SEM after cleaning 

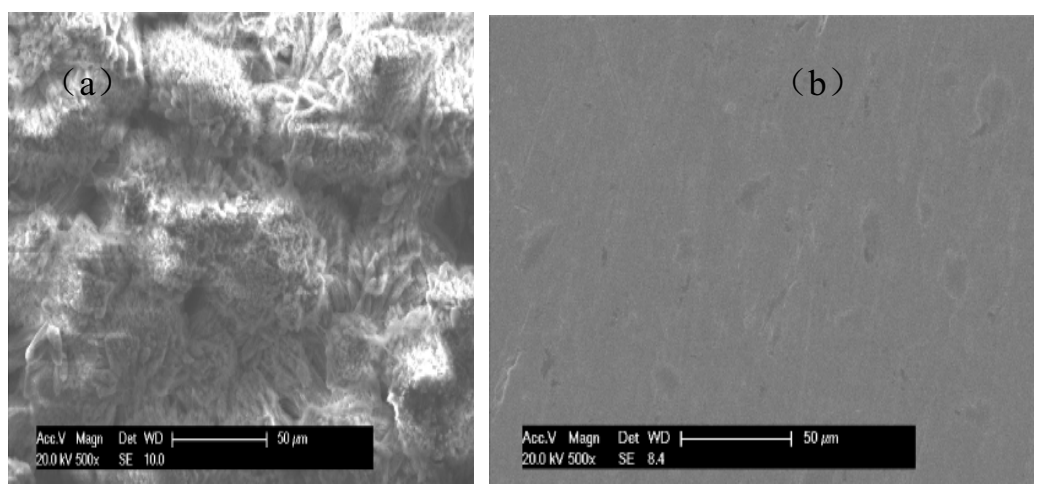

Figure7. SEM micrographs of B10 in galvanic couple B10/921A in seawater at $15^{\circ} \mathrm{C}$ :

(a) SEM before cleaning, (b) SEM after cleaning

The corrosion behavior of $\mathrm{Cu}-\mathrm{Ni}$ Alloy(B10)/high strength steel(921A) has been characterized in natural seawater at $0,5,15,25,35,45$ and $65^{\circ} \mathrm{C}$ for $240 \mathrm{~h}$. The following conclusions can be drawn:

(i) The order of corrosion sensitivity of the uncoupled single phases is: Cu-Ni Alloy (B10) $<$ high strength steel (921A).

(ii) The 921A acts as the anode and B10 act as the cathode in galvanic corrosion couple $\mathrm{B} 10 / 921 \mathrm{~A}$. The galvanic reaction is mainly governed by the anodic oxidation of the $921 \mathrm{~A}$, which is the highest active and least polarized.

(iii) The influence of temperature is an important factor to determine the self-corrosion and galvanic corrosion rate. Increasing temperature accelerated both of electrochemical corrosion.

\section{Acknowledgments}

This work was financially supported by "the National Natural Science Foundation of China (No.51509044)".

\section{References}

1. M. Schumacher, Seawater corrosion handbook. USA:Noyes Data Corporation, NJ, USA. 1979.

2. J.W. Oldfield, ASTM STP 978, ASTM, West Conshohocken, PA, 1988, pp. 5.

3. F.T. Cheng, K.H. Lo, H.C. Man, Surface and Coatings Technology 172, 2003, pp.316.

4. K.R. Trethewey, D.A. Sargeant, Metals and Materials, vol. 8, 1992, pp. 378-382.

5. R. Baboian, ASTM STP 516, ASTM, Philadelphia, PA,1972, pp. 145.

6. F. E. Varela, Y. Kuratat, N. Sanada,, Corrosion Science, Vol. 39, No.4, 1997, pp. $775-788$

7. G.W. Warren, G. Gao and Q. Li, J. Appl. Phys. 70 1991,pp.6609. 